\title{
Hydrodynamics of the Pilot Scale Wet Scrubber with Restricted Outlet Absorbent Flow Rate
}

\author{
Samwel Victor Manyele \\ Department of Chemical and Mining Engineering, College of Engineering and Technology, \\ University of Dar es Salaam, Dar es Salaam, Tanzania \\ Email: smanyele@udsm.ac.tz
}

Received February 24, 2012; revised April 20, 2012; accepted April 30, 2012

\begin{abstract}
This paper presents the hydrodynamics of the wet scrubber coupled to a pilot CFB incineration facility. The scrubber was operated using tap water as a scrubbing liquid. The outlet liquid flow rate, $\mathrm{Q}_{\mathrm{o}}$, and accumulation rate, $\mathrm{Q}_{\mathrm{a}}$, strongly depend on the inlet liquid flow rate, $\mathrm{Q}_{\text {in }}$, with different profiles. At higher $\mathrm{Q}_{\text {in }}$ values, $\mathrm{Q}_{\mathrm{o}}$ stabilizes, leading to higher $\mathrm{Q}_{\mathrm{a}}$ and finally flooding. The values of $Q_{a}$ were higher than $Q_{o}$ except for $Q_{\text {in }}$ ranging between 0.53 and $0.72 \mathrm{~L} / \mathrm{s}$ (safe operating range) in which $\mathrm{Q}_{\mathrm{a}} \cong \mathrm{Q}_{\mathrm{o}}$ and $\mathrm{Q}_{\mathrm{a}}=\mathrm{Q}_{\text {in }} / 2$. The outlet-to-inlet liquid flow rate ratio, $\mathrm{Q}_{\mathrm{o}} / \mathrm{Q}_{\text {in }}$ decreased for $\mathrm{Q}_{\mathrm{in}}>0.53$ $\mathrm{L} / \mathrm{s}$. The increase in the accumulation-to-inlet liquid flow rate ratio, $\mathrm{Q}_{\mathrm{a}} / \mathrm{Q}_{\mathrm{in}}$, at higher $\mathrm{Q}_{\text {in }}$ indicates a change in flow regime towards flooding, accompanied by an abrupt increase in the height of accumulating liquid, $\mathrm{H}_{\mathrm{a}}$. The difference between $\mathrm{Q}_{\mathrm{a}} / \mathrm{Q}_{\text {in }}$ and $\mathrm{Q}_{\mathrm{o}} / \mathrm{Q}_{\text {in }}$ (denoted as, $\Delta \mathrm{Q}_{\mathrm{ao}} / \mathrm{Q}_{\mathrm{in}}$ ), shows a minimum close to zero in the safe operating range. The gas flow rate towards the wet scrubber had slight effect on $\mathrm{Q}_{0}$ and $\mathrm{Q}_{\mathrm{a}}$ when $\mathrm{Q}_{\text {in }}$ was maintained constant. The ratio $\mathrm{Q}_{\mathrm{o}} / \mathrm{Q}_{\text {in }}$ decreased slightly with $\mathrm{H}_{\mathrm{a}} / \mathrm{H}_{\mathrm{t}}$ irrespective of gas velocity. Changing the liquid-to-gas ratio, $\mathrm{L} / \mathrm{G}$ and $\mathrm{Q}_{\text {in }}$ strongly affects the maximum and minimum values of $\mathrm{Q}_{0} / \mathrm{Q}_{\text {in }}$ and $\mathrm{Q}_{\mathrm{a}} / \mathrm{Q}_{\text {in }}$.
\end{abstract}

Keywords: Wet Scrubber; Liquid Accumulation Rate; Liquid Accumulation Level; Outlet Liquid Flow Rate; Liquid-to-Gas Ratio; Valve Opening Position; Incineration

\section{Introduction}

Wet scrubbers are wet collection devices for fumes, mists and suspended dusts used in air pollution control systems [1]. Other air pollution control devices for dusts control include electrostatic precipitators [2], cyclones [3], bag houses [2,4-6], etc. Wet scrubbers collect particles by direct contact with a liquid (usually water or lime water). Wet scrubbers have been used for air pollution control in incineration and waste-to-energy processes [7]. There are multitudes of scrubber designs grouped according to the liquid contacting mechanism used. In addition, scrubbers can be broadly classified as low-, moderate-, or highenergy units depending on how the liquid is introduced into the scrubber [8]. Energy requirements in wet scrubbers can be expressed as the pressure drop across the scrubber or by the level of contacting power, expressed as $\mathrm{kWh} / \mathrm{m}^{3}$ gas treated [9]. The most common units of measurement for contacting power are $\mathrm{kWh} / 1000 \mathrm{~m}^{3}$ of gas, while the liquid circulation rates are given in liters per $\mathrm{m}^{3}$ of gas [10-12].

During wet scrubber operation, the liquid inlet flow rate corresponding to the existing gas flow rate is determined from mass balance equations. However, the outlet liquid flow rate is normally less than the inlet liquid flow rate due to some of the liquid accumulating in the bottom of the scrubber. The advantages of the liquid accumulation include sealing effect provided which prevents the flue gas from short-circuiting to the scrubbing solution tank and also as a cooling agent for the incoming hot gases. However, the critical disadvantage of liquid accumulation is the possibility of flooding, which occurs when the liquid level in wet scrubber becomes excessively high leading to overflow of the liquid towards the gas inlet pipe and thus interfering with the combustion process.

This paper investigates the hydrodynamics of the wet scrubber based on inlet and outlet liquid flow rates, accumulation rate for the liquid in the wet scrubber bottom (expressed as the accumulation rate and accumulation height), gas flow rate, liquid outlet control valve opening position, liquid-to-gas ratio, etc.

\section{Literature Review}

Wet scrubbers rely on a liquid spray to remove gaseous emissions, with particulate control as a secondary function. The major types of wet scrubbers are venturi scrubbers, jet (fume) scrubbers, and spray towers or chambers. Venturi scrubber's consume large quantities of 
scrubbing liquid and electric power and incur high pressure drops. Jet or fume scrubbers rely on the kinetic energy of the liquid stream. The typical removal efficiency of a jet or fume scrubber (for particles $10 \mathrm{~mm}$ or less) is lower than that of a venturi scrubber. Spray towers can handle larger gas flows with minimal pressure drop. Spray towers are also used as gas coolers where the hot gases are cooled prior to exiting the process to the environment.

Because wet scrubbers may contribute to corrosion, removal of water from the effluent gas from scrubbers may be necessary. Another consideration is that wet scrubbing results in a liquid effluent contaminated with solids present in the gas stream. Wet scrubbing technology is used where the contaminant cannot be removed easily in a dry form, for soluble gases and wettable particles, and if the contaminant will undergo some subsequent wet process (such as recovery, wet separation or settling, or neutralization). Gas flow rates range from 20 to 3000 $\mathrm{m}^{3} / \mathrm{min}$. Gas flow rates approximately $2000 \mathrm{~m}^{3} / \mathrm{min}$ may have a corresponding pressure drop of $25 \mathrm{~cm} \mathrm{H} \mathrm{H}_{2} \mathrm{O}$ colu$\mathrm{mn}$ [13]. Figure 1 shows the typical wet scrubber designs.
Wet scrubbers capture relatively small dust particles with large liquid droplets. In most wet scrubbing systems, droplets produced are generally larger than $50 \mu \mathrm{m}$ (in the 150 to 500 micrometer range). The size distribution of particles to be collected is source specific. For example, particles produced by mechanical means (crush or grind) tend to be large (above $10 \mu \mathrm{m}$ ); whereas, particles produced from combustion or a chemical reaction will have a substantial portion of small (i.e., less than $5 \mu \mathrm{m}$ ) and submicrometer-sized particles. Several mechanisms for particle removal in a wet scrubbing system are summarized in Table 1.

The most critical sized particles are those in the 0.1 to $0.5 \mu \mathrm{m}$ range because they are the most difficult for wet scrubbers to collect. A relationship between particle size and collection efficiency for typical wet scrubber exist, such that from $0.1 \mu \mathrm{m}$, the collection efficiency drops below $90 \%$ and increases again beyond $0.5 \mu \mathrm{m}$ reaching about $100 \%$ at $2 \mu \mathrm{m}$ and above.

In order to properly design a particulate wet scrubber, one must obtain as much information as possible concerning the characteristics of the flue gas stream to be treated. This information must be obtained or estimated

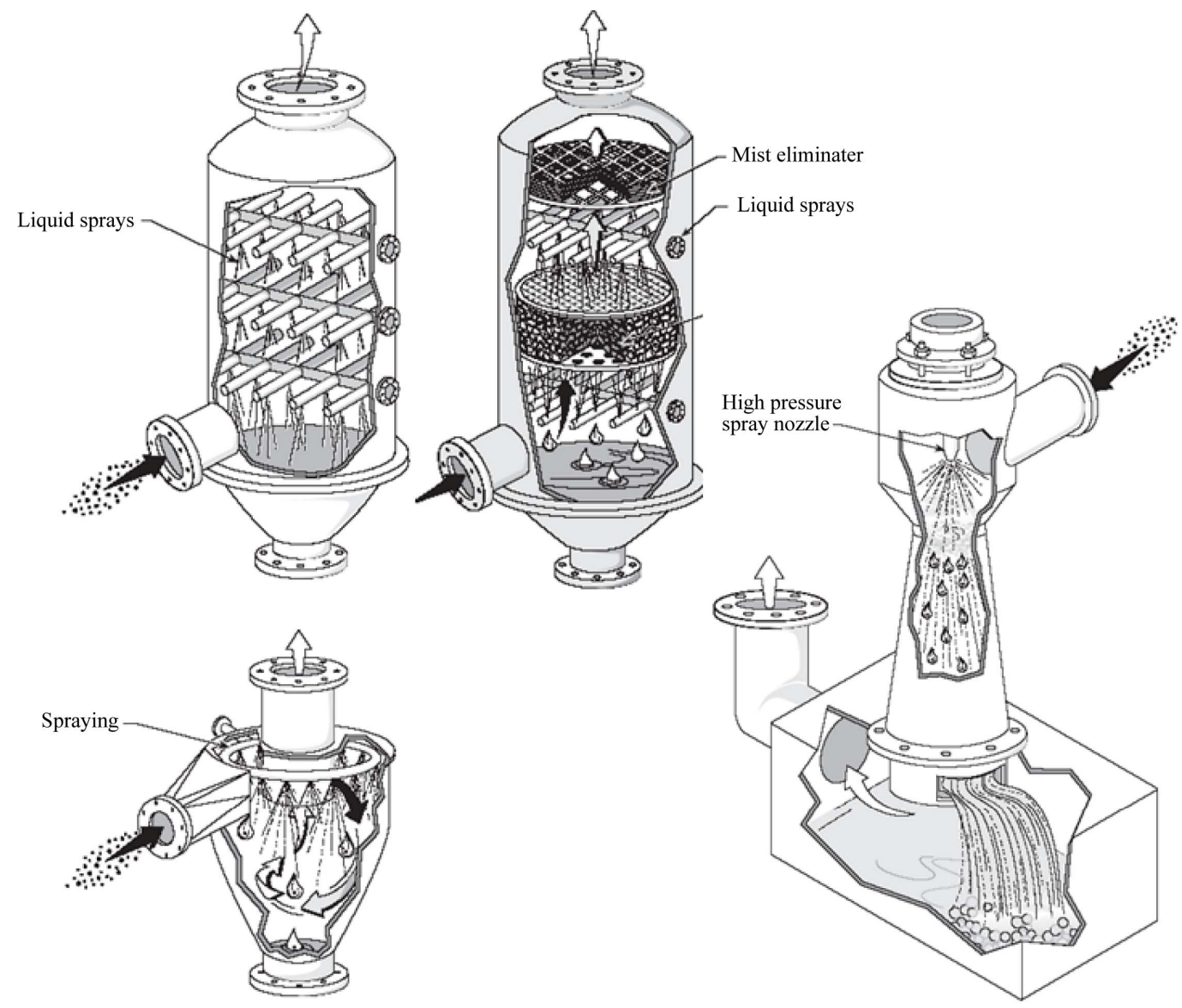

Figure 1. Typical designs for wet scrubber configurations (spray chamber, counter-current-flow packed tower, irrigated cyclone scrubber, and venturi scrubber). 
Table 1. Particle collection mechanisms for wet scrubbing systems.

\begin{tabular}{|c|c|}
\hline Mechanism & Explanation \\
\hline Impaction & Particles too large to follow gas streamlines around a droplet collide with it. \\
\hline Diffusion & Very tiny particles move randomly, colliding with droplets because they are confined in a limited space. \\
\hline Direct interception & $\begin{array}{l}\text { An extension of the impaction mechanism. The center of a particle follows the streamlines around the droplet, but a collision } \\
\text { occurs if the distance between the particle and droplet is less than the radius of the particle. }\end{array}$ \\
\hline $\begin{array}{l}\text { Electrostatic } \\
\text { attraction }\end{array}$ & Particles and droplets become oppositely charged and attract each other. \\
\hline Condensation & When hot gas cools rapidly, particles in the gas stream can act as condensation nuclei and, as a result, become larger. \\
\hline Centrifugal force & $\begin{array}{l}\text { The shape or curvature of a collector causes the gas stream to rotate in a spiral motion, throwing larger particles toward the } \\
\text { wall. }\end{array}$ \\
\hline Gravity & Large particles moving slowly enough will fall from the gas stream and be collected. \\
\hline
\end{tabular}

for both the average and maximum ranges that will occur. During combustion, for instance, the gas flow rate always exceeds the blower capacity due to additional gases generated. Scrubbing systems must be able to operate effectively at both the normal day-to-day conditions as well as to accommodate any maximum ranges.

There are a number of parameters that affect particle and acid gas removal efficiency and must be considered in the design of a wet scrubbing system, that is, dust properties (particle size distribution being most important), exhaust gas characteristics, static pressure drop [13], scrubber liquid flow rate [12], required particle removal efficiencies, and removal of entrained liquid droplets.

Dust properties include particle size distribution, concentration and chemical composition. The particle size distribution is the most important factor that affects scrubber design and operation. However, particle size distribution data is rarely available for most sources and generally must be estimated from similar type sources. The average and maximum particle concentrations (or grain loading) must be obtained to properly size the scrubber and the solids removal system. For incinerators, grain loading depends on amount of fly ash escaping from the primary and secondary combustion chambers. The chemical composition of the dust particle is important as it determines if the material will cause any plugging problems or precipitate problems.

Liquid flow rate is based on the gas flow rate, temperature in the scrubber, compensation for evaporation rate and type of scrubbing system utilized. Values need to be identified for both normal and maximum operating conditions. Also, for the extended life of pumps, the recirculation rate and permissible levels of suspended solids in the recirculated liquid need to be identified. In this study, the scrubbing liquid is continuously pumped into the scrubber at a high rate with recirculation.

\section{Materials and Methods}

Before you begin to format your paper, first write and save the content as a separate text file. Keep your text and graphic files separate until after the text has been formatted and styled. Do not use hard tabs, and limit use of hard returns to only one return at the end of a paragraph. Do not add any kind of pagination anywhere in the paper. Do not number text heads - the template will do that for you.

Finally, complete content and organizational editing before formatting. Please take note of the following items when proofreading spelling and grammar:

\subsection{Process Description}

The test series consisted of runs with gas flow rates ranging from 0 to $14 \mathrm{~m} / \mathrm{s}$ and liquid flow rates ranging from 0.15 to $0.95 \mathrm{~L} / \mathrm{s}$. Different combinations of gas and liquid flow rates were used. Experiments were designed to study the hydrodynamics of the scrubber Stage 1, which is similar to Stage 2. The gas flow rate was controlled by using a flap on the blower suction side (connected to the wind box), while the inlet liquid flow rate from the pump was controlled using a gate valve connected to a flow meter. The flue gas from the combustion chamber exits the riser and passes through a series of cyclones for removing solid particles, heat exchanger for reducing temperature and finally passes through the multistage wet scrubbers. Figure 2 shows the experimental setup, incorporating a circulating fluidized bed incineration facility with multistage wet scrubbers used in this study.

\subsection{Varying the Outlet Valve Opening Position}

The outlet liquid flow rate from the wet scrubber was controlled using the valve connected to the outlet pipe at the bottom of the scrubber Stage 1. Three opening positions, $\mathrm{V}_{\mathrm{op}}$, were studied, that is full-open, 3/4-open, and $1 / 2$-open positions, as a means of controlling the outlet flow rate, $\mathrm{Q}_{0}$, thus, the assumed values of $\mathrm{V}_{\text {op }}$ were 1.0, 0.75 , and 0.5 , respectively. Lower values of $V_{\text {op }}$ were not tested because below 1/2-open position, the accumulation rate was exceedingly high leading to flooding of the scrubber. The outlet liquid flow rate was determined by 


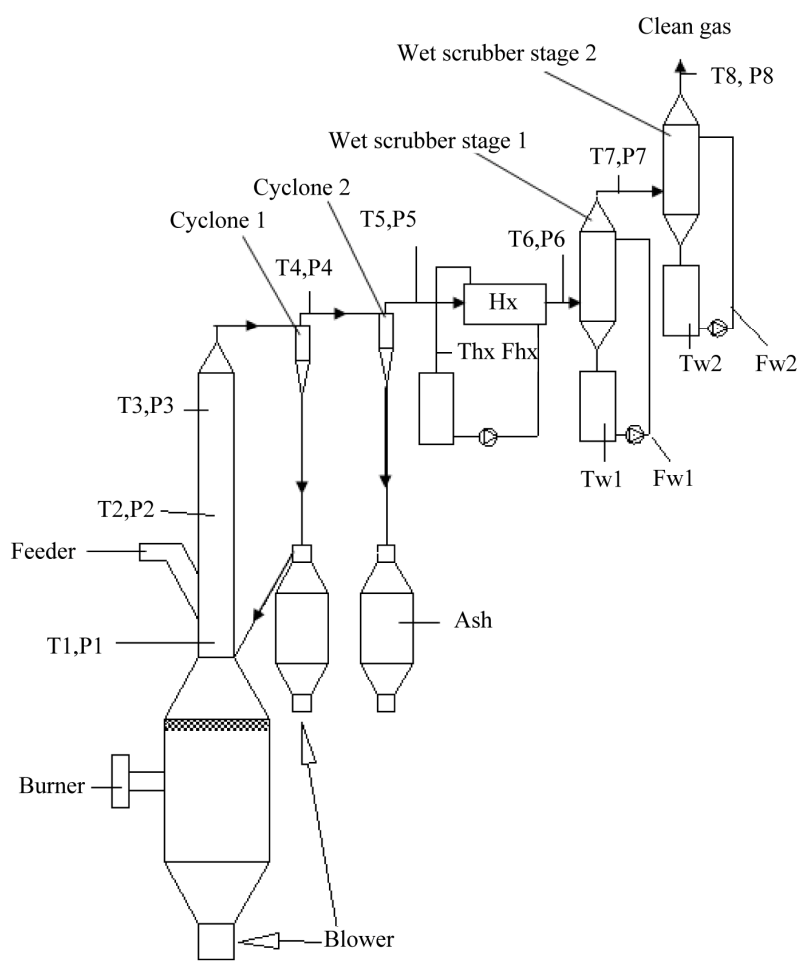

Figure 2. The experimental set up.

noting the time required to collect a known volume of liquid using a stopwatch. The average of three measurements was used to establish the outlet flow rate.

\subsection{Determination of Liquid Accumulation Rate in the Wet Scrubber}

A known flow rate of scrubbing liquid was introduced into the scrubber in the form of a spray directed downwards. The optimum operation of the wet scrubber was measured by using the scrubbing liquid level that remains within the scrubber, defined as liquid accumulation rate, $\mathrm{Q}_{\mathrm{a}}$. If the liquid accumulation rate is too high, the scrubbing liquid flows back to the heat exchanger, through the gas duct, and finally to the cyclones and combustion chamber. An accumulation liquid level was necessary in order to provide sealing effect to prevent the gas from short-circuiting to the scrubbing solution tank. This reason necessitated studying the water level within the scrubber bottom. The liquid accumulation rate was determined using Equation (1):

$$
\mathrm{Q}_{\mathrm{a}}=\mathrm{d}_{\mathrm{Q}}=\mathrm{Q}_{\mathrm{in}}-\mathrm{Q}_{\mathrm{o}}
$$

The liquid accumulation data was collected at different gas flow rates. The level of scrubbing liquid within the scrubber, $\mathrm{H}_{\mathrm{a}}$, was determined by reading the level of liquid in the level indicator tube. The data was collected by varying the inlet liquid flow rate from 0.15 to $0.95 \mathrm{~L} / \mathrm{s}$. There are three terms used for accumulation, these are:
Accumulation rate (dQ or $\mathrm{Q}_{\mathrm{a}}$ ) is the amount of scrubbing liquid retained in the wet scrubber per unit time; liquid accumulation height $\left(\mathrm{H}_{\mathrm{a}}\right)$ is the height occupied by scrubbing liquid retained in the wet scrubber; and, effective height $\left(\mathrm{H}_{\mathrm{e}}=\mathrm{H}_{\mathrm{t}}-\mathrm{H}_{\mathrm{a}}\right)$, which is the height of wet scrubber used for scrubbing processes between the liquid level and top of the scrubber. Thus, accumulation reduces the available space for mass and heat transfer in the wet scrubber.

The difference between $\mathrm{Q}_{\mathrm{a}}$ and $\mathrm{Q}_{\mathrm{o}}$ was determined from Equation (2):

$$
\mathrm{Q}_{\mathrm{ao}}=\mathrm{Q}_{\mathrm{a}}-\mathrm{Q}_{\mathrm{o}}
$$

\subsection{Liquid Flow Rate Ratios}

Two ratios were defined in order to normalize the wet scrubber data, so that it can be used in any scale of operation. The outlet-to-inlet liquid flow rate ratio, $\mathrm{Q}_{\mathrm{o}} / \mathrm{Q}_{\mathrm{in}}$, is the ratio between outlet flow rate and inlet flow rate, data of which eliminates the scale dependency of the results. Another useful quantity is the accumulation-to-inlet liquid flow rate ratio, $\mathrm{Q}_{\mathrm{a}} / \mathrm{Q}_{\mathrm{in}}$, which is the ratio between liquid accumulation rate and the inlet flow rate. The difference between the two quantities was estimated as per Equation (3):

$$
\frac{\Delta \mathrm{Q}_{\mathrm{ao}}}{\mathrm{Q}_{\mathrm{in}}}=\frac{\mathrm{Q}_{\mathrm{a}}-\mathrm{Q}_{\mathrm{o}}}{\mathrm{Q}_{\text {in }}}
$$

\subsection{Determination of the Liquid-to-Gas Ratio}

The liquid to gas ratio was calculated by dividing the liquid flow rate $(\mathrm{L} / \mathrm{s})$ by the flow rate of the gas in the wet scrubber $\left(\mathrm{m}^{3} / \mathrm{s}\right)$ giving $\mathrm{Q} / \mathrm{G}$ in litres of liquid per $\mathrm{m}^{3}$ of gas $\left(\mathrm{L} / \mathrm{m}^{3}\right)$, as shown in Equation (4):

$$
\frac{L}{G}\left(\frac{L}{m^{3}}\right)=\frac{Q\left(\frac{L}{s}\right)}{G\left(\frac{m^{3}}{s}\right)}
$$

Each velocity of the gas applied was multiplied by the cross-sectional area of the duct of the blower to get volumetric flow rate of gas in $\mathrm{m}^{3} / \mathrm{s}$.

\section{Results and Discussion}

\subsection{Variation of $Q_{0}$ with $Q_{\text {in }}$}

Figure 3 shows the variation of $Q_{0}(L / s)$ with $Q_{\text {in }}(L / s)$ at variation gas velocities in the combustion chamber, $\mathrm{U}_{\mathrm{g}}$ $(\mathrm{m} / \mathrm{s})$, when the scrubbing solution outlet valve is full open, 3/4-open and 1/2-open. The curves have similar shapes for all valve opening positions, that is, increasing initially and stabilizing for $\mathrm{Q}_{\text {in }}>0.8 \mathrm{~L} / \mathrm{s}$ as reported also by Said et al. (2010). Stabilizing curves indicate that $\mathrm{Q}_{0}$ 

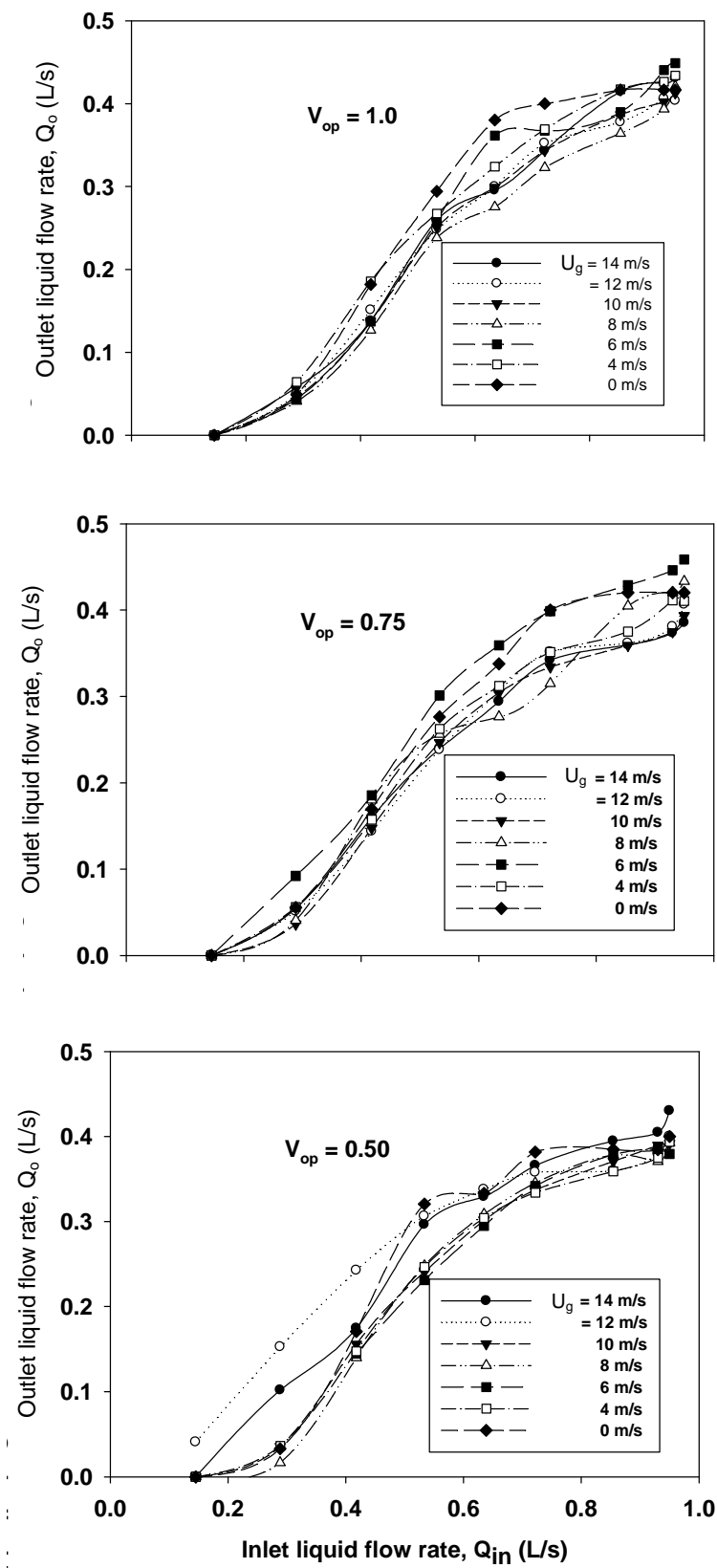

Figure 3. Variation of the outlet liquid flow rate with the inlet liquid flow rate at different valve opening position and flue gas velocities.

ceases to increase, implying that also that $\mathrm{Q}_{\mathrm{a}}$ increases further (based on Equation (1)) which can lead to flooding. Thus, $\mathrm{Q}_{\text {in }}=0.8 \mathrm{~L} / \mathrm{s}$ is assumed to be the maximum inlet liquid flow rate. In all combinations of operating conditions of $\mathrm{U}_{\mathrm{g}}, \mathrm{Q}_{\mathrm{in}}$, and $\mathrm{V}_{\mathrm{op}}, \mathrm{Q}_{\mathrm{o}}$ is less than $\mathrm{Q}_{\text {in }}$ indicating that there is always liquid accumulating in the wet scrubber. There is a delay in the appearance of $\mathrm{Q}_{0}$, which signifies that there is also a minimum inlet flow rate at which the scrubbing solution flows outside the scrubber, that is when $\mathrm{Q}_{\text {in }}>0.2 \mathrm{~L} / \mathrm{s}$, as shown in Figure 3. The minimum liquid flow rate into the scrubber depends on gas velocity and valve opening position.

\subsection{Dependency of $Q_{a}$ on $Q_{\text {in }}$}

The variation of $Q_{a}$ with $Q_{\text {in }}$ (Figure 4) shows different profiles compared to those of $\mathrm{Q}_{0}$. Despite the general increase in $\mathrm{Q}_{\mathrm{a}}$ with increasing $\mathrm{Q}_{\text {in }}, \mathrm{Q}_{\mathrm{a}}$ stabilizes for $\mathrm{Q}_{\text {in }}$ ranging between 0.4 and $0.7 \mathrm{~L} / \mathrm{s}$ even when the outlet valve is open $\left(\mathrm{V}_{\text {op }}=1.0,0.75\right.$ and 0.5$)$. This behaviour was also reported by Said et al. (2010). The initial increase in $Q_{a}$ at very low values of $Q_{\text {in }}$ was not reported by former researchers because the range of $\mathrm{Q}_{\text {in }}$ was shorter,
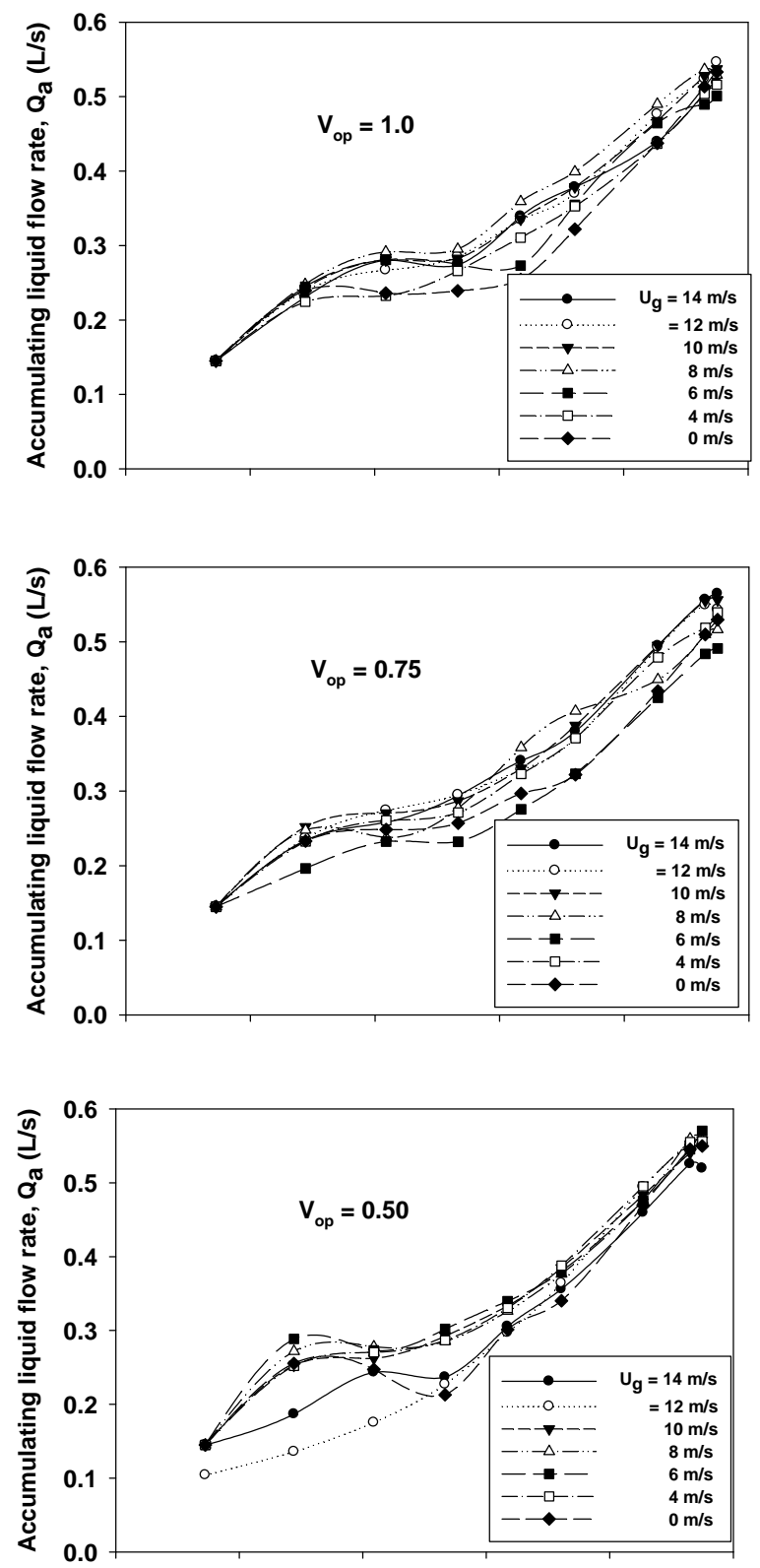

Figure 4. Variation of $Q_{a}$ with $Q_{\text {in }}$ in the scrubber at different outlet valve opening positions and the flue gas velocities. 
starting from $0.3 \mathrm{~L} / \mathrm{s}$ onwards different from minimum value used in this study, i.e., $\mathrm{Q}_{\text {in }}=0.1 \mathrm{~L} / \mathrm{s}$. Similar to results reported in literature [12], the effect of $U_{g}$ on $Q_{a}$ diminishes at higher $\mathrm{Q}_{\text {in }}$ higher than $0.7 \mathrm{~L} / \mathrm{s}$, below which, $\mathrm{Q}_{\mathrm{a}}$ increases sharply with $\mathrm{Q}_{\text {in }}$ for all valve opening positions. The accumulation rate can also be regarded as a cause of deviation of $Q_{o}$ from $Q_{i n}$. This deviation is important for safe operation of wet scrubbers connected to combustion systems which receive hot gases.

\subsection{Comparison between $Q_{0}$ and $Q_{a}$ at Different Valve Opening Position}

Based on the rsults presented in Figures 3 and 4, it is evident that a difference exists between $\mathrm{Q}_{\mathrm{a}}$ and $\mathrm{Q}_{\mathrm{o}}$ not only in actual values, but also in the way these parameters change with $\mathrm{Q}_{\text {in. }}$. Figure 5 presents the variation the average values of $Q_{o}$ and $Q_{a}$ values (averaged over all gas velocities) for the three valve positions (full-open, $3 / 4$-open and half-ope 3/4 with inlet scrubbing liquid flow rate, $\mathrm{Q}_{\text {in }}$. For $\mathrm{Q}_{\text {in }}<0.5 \mathrm{~L} / \mathrm{s}$, and $\mathrm{Q}_{\text {in }}>0.7, \mathrm{Q}_{\mathrm{a}}$ values are higher than $Q_{0}$. The values $Q_{o}$ and $Q_{a}$ are equal in the $\mathrm{Q}_{\text {in }}$ range between 0.5 and $0.7 \mathrm{~L} / \mathrm{s}$. Above half-open outlet valve position $\left(\mathrm{V}_{\mathrm{op}}>0.5\right)$, the valve opening position was observed to have a small effect on the outlet flow rate such that the averaged values for all gas flow rates fall almost on the same curve as shown in the Figure 5. Similarly, the average values of $\mathrm{Q}_{\mathrm{a}}$ for different air flow rates fall on the same curve, regardless of changes in valve opening positions for $\mathrm{V}_{\mathrm{op}}>0.5$. It is evident from Figure 5 that the $\mathrm{Q}_{\mathrm{o}}$ and $\mathrm{Q}_{\mathrm{a}}$ become equal for $\mathrm{Q}_{\text {in }}$ values ranging between 0.53 and $0.72 \mathrm{~L} / \mathrm{s}$, while before and after this range, $Q_{a}$, values are higher than $Q_{0}$. Superimposed in Figure 5, is the plot of the quantity $\Delta \mathrm{Q}_{\mathrm{ao}}$, that is, the difference between $Q_{a}$ and $Q_{o}$ against $Q_{\text {in. }}$. This difference shows a minimum turning point equal to zero for

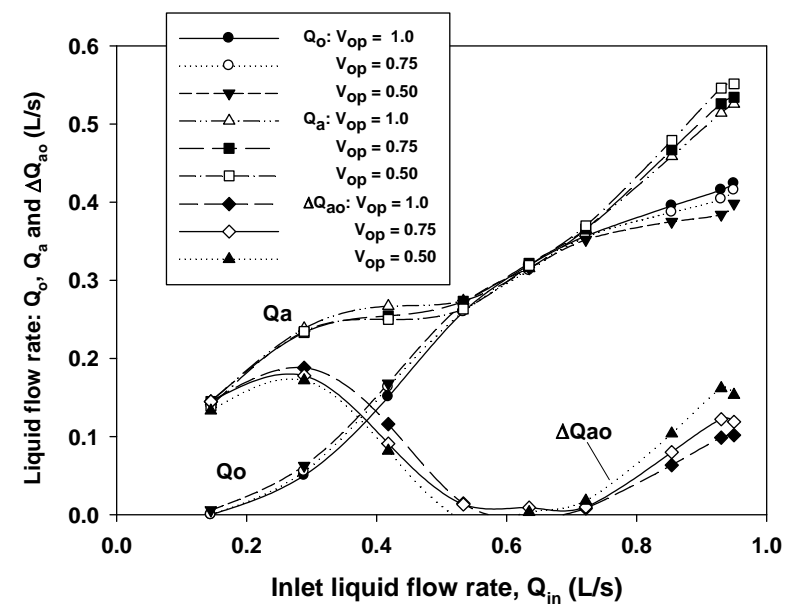

Figure 5. Comparison of the averaged outlet liquid flowrate and liquid accumulation rate in the wet scrubber at different valve opening positions.
Qin between 0.533 and $0.722 \mathrm{~L} / \mathrm{s}$.

\subsection{Dependnency of $Q_{o} / Q_{\text {in }}$ and $Q_{a} / Q_{\text {in }}$ Ratios on $Q_{\text {in }}$}

Figure 6 shows the variation of the ratio $\left(\mathrm{Q}_{\mathrm{o}} / \mathrm{Q}_{\text {in }}\right)$ with $\mathrm{Q}_{\text {in }}$ at different conditions of gas flow rate and valve opening positions. Initially, at low values of $\mathrm{Q}_{\text {in }}$, the ratio $\mathrm{Q}_{\mathrm{o}} / \mathrm{Q}_{\text {in }}$ increases faster, reaching a maximum value, location of which depends slightly on gas velocity, $\mathrm{U}_{\mathrm{g}}$ and valve opening position, $V_{o p}$. The values of $Q_{o} / Q_{\text {in }}$, however, decreases slightly after a maximum, An observation
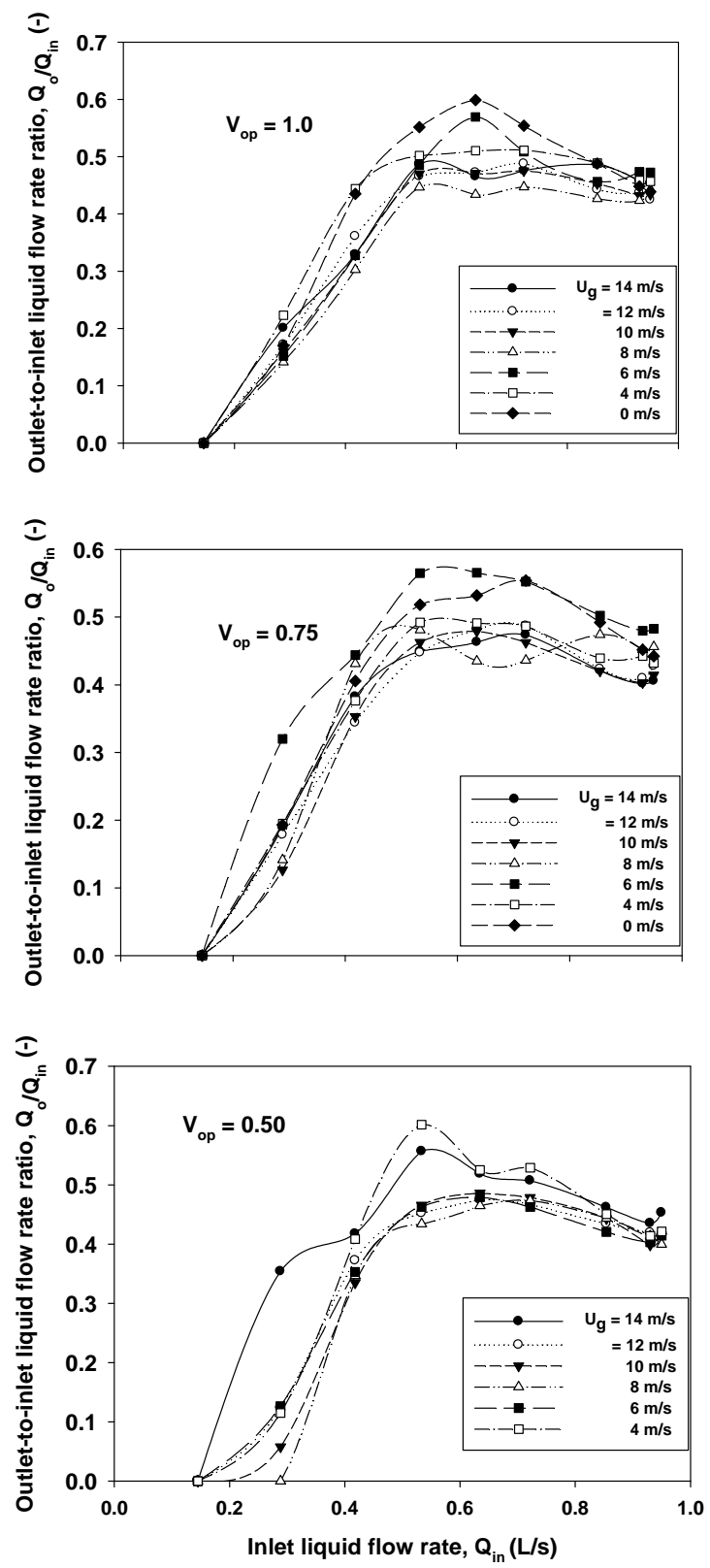

Figure 6. Variation of outlet-to-inlet liquid flow rate ratio with inlet liquid flow rate under different outlet valve opening position and gas velocites. 
which can be attributed to the fact that $\mathrm{Q}_{0}$ ceases to increase as $\mathrm{Q}_{\text {in }}$ is increased from 0.5 to $0.95 \mathrm{~L} / \mathrm{s}$ such that the ratio $\mathrm{Q}_{\mathrm{o}} / \mathrm{Q}_{\text {in }}$ decreases also, as reported also in Figure 3. It should be noted that $\mathrm{Q}_{\mathrm{o}} / \mathrm{Q}_{\text {in }}$ do not exist for $\mathrm{Q}_{\text {in }}<0.2$ $\mathrm{L} / \mathrm{s}$ because no outlet liquid flow is observed at very low values of $Q_{\text {in }}$.

Figure 7 shows the variation of $Q_{a} / Q_{\text {in }}$ ratio with $Q_{\text {in }}$
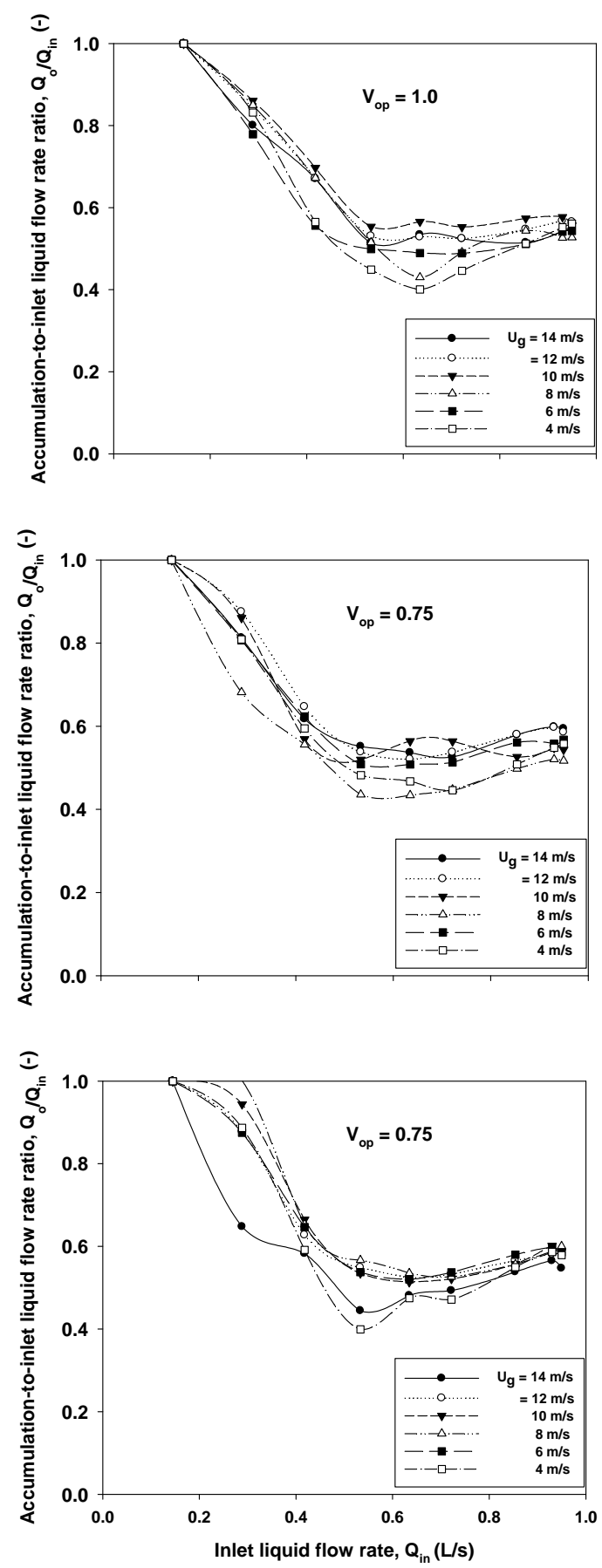

Figure 7. Variation of accumulation-to-inlet liquid flow rates with $Q_{\text {in }}$ under different outlet valve opening positions and gas velocities. for different valve opening positions and gas flow rates. Different from $\mathrm{Q}_{\mathrm{o}} / \mathrm{Q}_{\mathrm{in}}, \mathrm{Q}_{\mathrm{a}} / \mathrm{Q}_{\mathrm{in}}$ decreases with increasing $Q_{\text {in }}$ until a minimum point is reached beyond which $\mathrm{Q}_{\mathrm{a}} / \mathrm{Q}_{\text {in }}$ increases slightly.

However, both ratios show turning points so that a quadratic relationship is depicted between these parameters. This shows that as $\mathrm{Q}_{\text {in }}$ is increased beyond $0.5 \mathrm{~L} / \mathrm{s}$ the accumulation rate is low compared to $\mathrm{Q}_{\text {in }}$, but beyond the minimum point $\mathrm{Q}_{\mathrm{a}}$ is still lower than $\mathrm{Q}_{\text {in }}$ but higher compared to the original values. The fact $\mathrm{Q}_{\mathrm{a}} / \mathrm{Q}_{\text {in }}$ starts at 1.0 is because initially all the liquid entering the scrubber do not flow out $\left(Q_{o}=0\right)$ at lower $Q$ in values and $Q_{a}=Q_{\text {in }}$. For $\mathrm{Q}_{\text {in }}<0.2 \mathrm{~L} / \mathrm{s}, \mathrm{Q}_{\mathrm{a}} / \mathrm{Q}_{\text {in }}=1.0$ indicating that all the liquid entering the wet scrubber accumulates with $\mathrm{Q}_{\mathrm{o}}=0$. This is because, at low inlet liquid flow rate, the accumulating liquid is filing the wet scrubber bottom and no outlet flow is observed.

Figure 8 compares the ratios $\mathrm{Q}_{\mathrm{a}} / \mathrm{Q}_{\text {in }}$ and $\mathrm{Q}_{\mathrm{o}} / \mathrm{Q}_{\text {in }}$ at various $\mathrm{Q}_{\text {in }}$ values and valve opening positions. The two ratios are equal when $Q_{\text {in }}=0.5$ to 0.7 where they are equal to 0.5 . The curves are opposite in nature because $\mathrm{Q}_{\text {in }}=\mathrm{Q}_{\mathrm{a}}+\mathrm{Q}_{\mathrm{o}}$. In general, $\mathrm{Q}_{\mathrm{a}}$ is higher than $\mathrm{Q}_{\mathrm{o}}$, except for the $\mathrm{Q}_{\text {in }}$ values from 0.5 to $0.7 \mathrm{~L} / \mathrm{s}$. Superimposed in Figure 8 is the variation of the ratio $\Delta Q_{a 0} / Q_{\text {in }}$ with $Q_{\text {in }}$. Initially, the difference between $\mathrm{Q}_{\mathrm{a}} / \mathrm{Q}_{\text {in }}$ and $\mathrm{Q}_{\mathrm{o}} / \mathrm{Q}_{\text {in }}$ is very high but drops to zero when $\mathrm{Q}_{\text {in }}$ reaches 0.53 to $0.75 \mathrm{~L} / \mathrm{s}$. Beyond this range, $\Delta \mathrm{Q}_{\mathrm{ao}} / \mathrm{Q}_{\text {in }}$ increases again due to abrupt increase in $\mathrm{Q}_{\mathrm{a}}$ as flow regime approaches flooding. The re-surfacing of the ratio $\Delta \mathrm{Q}_{\mathrm{ao}} / \mathrm{Q}_{\text {in }}$ is an indication that the flow regime is the wet scrubber is changing towards flooding regime.

\subsection{Effect of Gas Flow Rate on $\mathbf{Q}_{o}$ and $\mathbf{Q}_{\mathbf{a}}$}

The flow of hot gases into the wet scrubber and evaporating water increases the pressure in the scrubber shell.

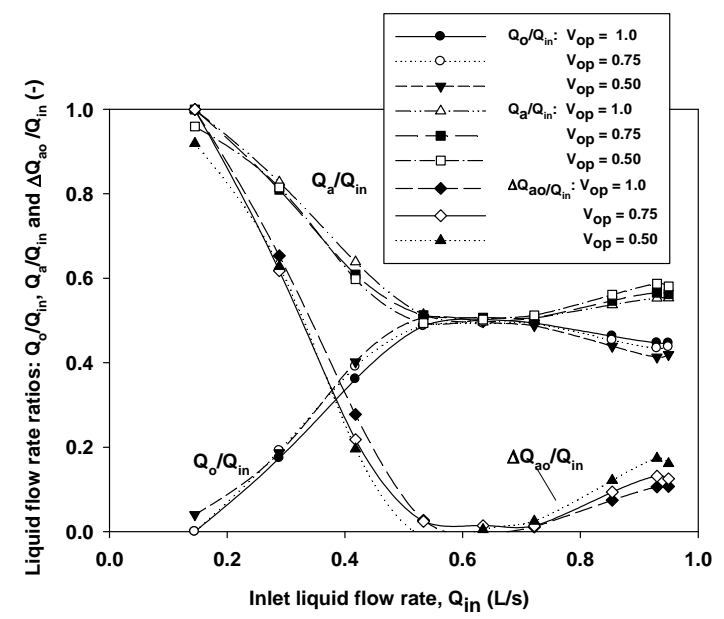

Figure 8. Comparison of outlet-to-inlet and accumulationto-inlet flow rate ratios in the wet scrubber under different outlet valve opening positions. 
As a result, the pressure at the top of the accumulating liquid surface is expected to increase the outlet liquid flow rate. However, the trend was observed to be strongly dependent on $Q_{\text {in }}$ than on $U_{g}$. Figure 9 shows the variation of $\mathrm{Q}_{0}$ and $\mathrm{Q}_{\mathrm{a}}$ with gas velocity $\mathrm{U}_{\mathrm{g}}$ at different inlet liquid flow rates. Results show that both $\mathrm{Q}_{\mathrm{a}}$ and $\mathrm{Q}_{o}$ are independent of $\mathrm{U}_{\mathrm{g}}$ but rather depend strongly on $\mathrm{Q}_{\mathrm{in}}$. The higher the inlet liquid flow rate, $Q_{\text {in }}$, the higher the outlet liquid flow rate, $\mathrm{Q}_{\mathrm{o}}$, and the liquid accumulation rate, $\mathrm{Q}_{\mathrm{a}}$. Under incineration conditions, $U_{g}$ will increase beyond gas flow forced by blower, but will not strongly affect $Q_{a}$ and $\mathrm{Q}_{\text {in }}$ as shown in Figure 9. Moreover, the increase in $\mathrm{Q}_{\text {in }}$ due to generation of the flue gas is shown to have no effect on the hydrodynamics of the wet scrubber.

\subsection{Effect of $Q_{a}$ and $H_{a}$ on Outlet Liquid Flow Rate}

Both $\mathrm{H}_{\mathrm{a}}$ and $\mathrm{Q}_{\mathrm{a}}$ affects the outlet liquid flow rate from the scrubber. Increasing $\mathrm{H}_{\mathrm{a}}$ adds hydrostatic head which pushes the accumulated liquid downward, hence increasing the outlet flow rate. Figure 10 shows the effect of $H_{a}$ on the outlet liquid flow rate, $Q_{o}$ (at $1 / 2$ open valve position). In general, $\mathrm{Q}_{o}$ increases with $\mathrm{H}_{\mathrm{a}}$ showing that
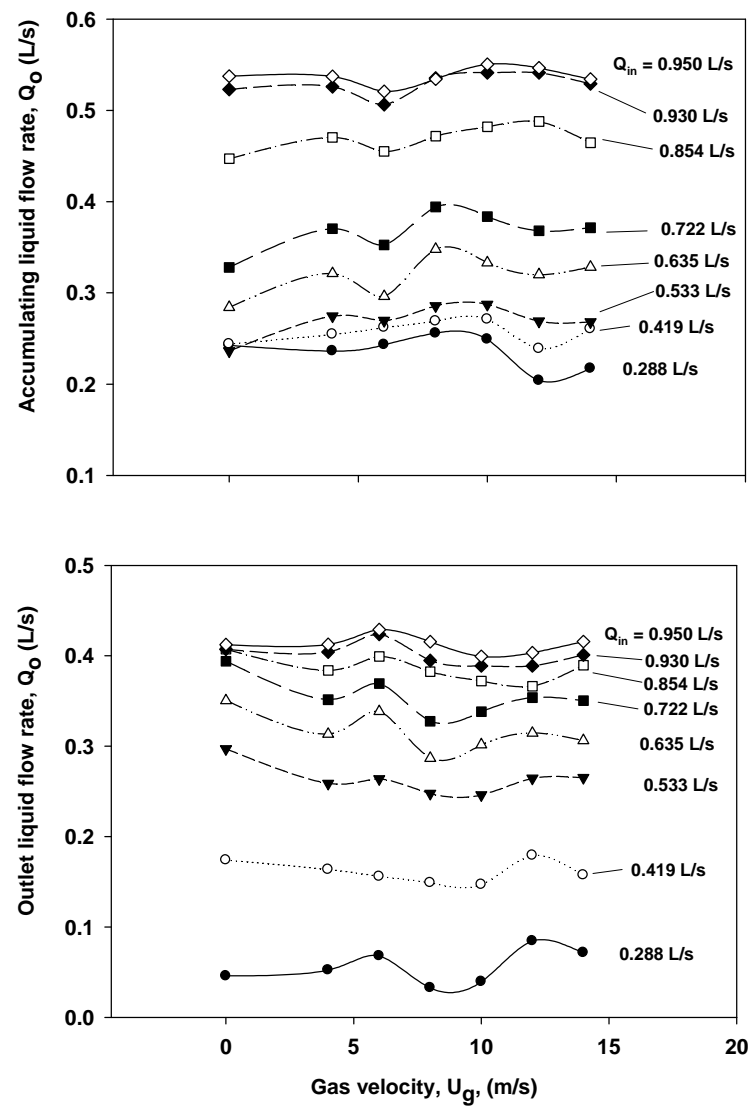

Figure 9. Variation of the outlet liquid flow rate and accumulation rate in the liquid scrubber with gas velocity at different inlet liquid flow rate.
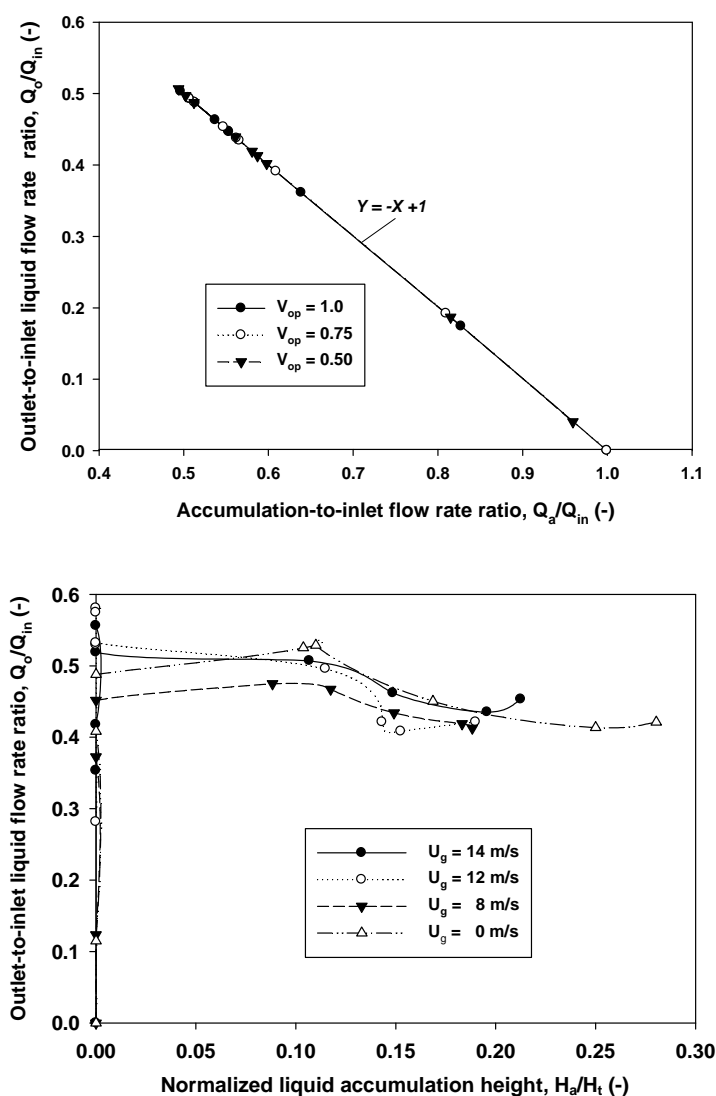

Figure 10. Dependence of $Q_{0}$ on $Q_{a}$ and $H_{a}$ in the wet scrubber at different gas velocities (when the valve is half-open).

the hydrostatic head created by the accumulating liquid increases the scrubbing liquid outlet flow rate. However, $\mathrm{Q}_{0}$ depends also on the gas flow rate, which creates high pressure in the effective height of the scrubber, hence increasing $\mathrm{Q}_{\mathrm{o}}$ and minimizing $\mathrm{H}_{\mathrm{a}}$ and $\mathrm{Q}_{\mathrm{a}}$.

At lower $Q_{a}$ values, $Q_{o}$ is very low, and remains constant until $\mathrm{Q}_{\mathrm{a}}$ is higher than $0.2 \mathrm{~L} / \mathrm{s}$, where the former increases abruptly. For $\mathrm{Q}_{\mathrm{a}}>0.4 \mathrm{~L} / \mathrm{s}, \mathrm{Q}_{\mathrm{o}}$ stabilizes at about $0.4 \mathrm{~L} / \mathrm{s}$, which corresponds to $\mathrm{Q}_{\text {in }}$ in the range of 0.533 to $0.722 \mathrm{~L} / \mathrm{s}$ as observed in Figures 3 and 5. The behaviour shown in Figure $\mathbf{1 0}$ can be attributed to the balance between gas pressure in the equivalent scrubber height and the hydrostatic head of the accumulated liquid corresponding to $\mathrm{H}_{\mathrm{a}}$.

\subsection{Effect of L/G Ratio on the Outlet Liquid Flow Rate}

The $\mathrm{L} / \mathrm{G}$ ratio is a combination of two parameters: liquid inlet flow rate, $Q_{\text {in }}$ and gas flow rate $Q_{g}$. The effect of changing $L / G$ ratio on the wet scrubber hydrodynamics was studied in order to establish the proper operating conditions for the wet scrubber. Figure 11 shows the effect of increasing $\mathrm{L} / \mathrm{G}$ ratio on the outlet liquid flow rate, $Q_{o}$, at different values of $Q_{i n}$. The range of values of 


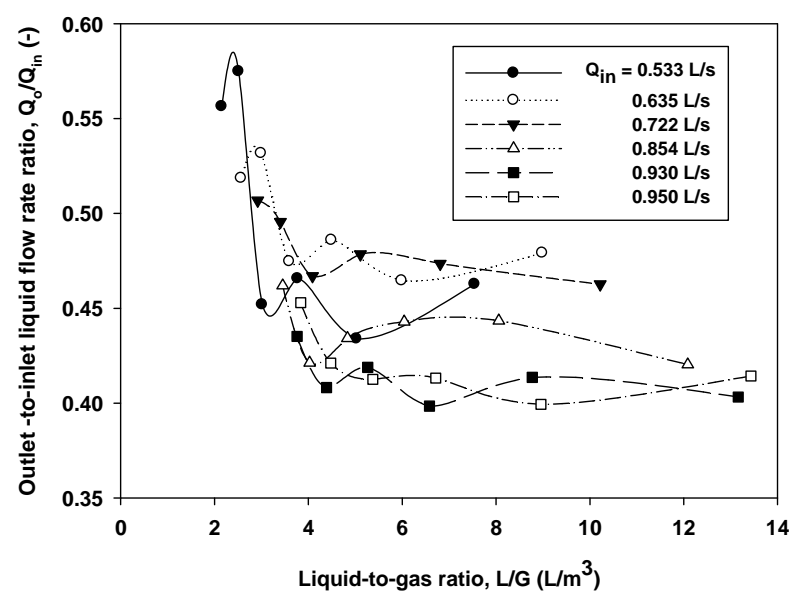

Figure 11. Mapping of $Q_{0}$ values at different liquid-to-gas ratios and specific inlet liquid flow rates in the wet scrubber.

$\mathrm{L} / \mathrm{G}$ observed in the wet scrubber increases with increasing value of $Q_{\text {in }}$, such that very narrow range exit at lower values of $\mathrm{Q}_{\text {in }}$ (for instance, $0.288 \mathrm{~L} / \mathrm{s}$ ) and very wide range of $\mathrm{L} / \mathrm{G}$ at higher values of $\mathrm{Q}_{\text {in }}$ (that is, 0.95 $\mathrm{L} / \mathrm{s}$ ). The curves at different values of $\mathrm{Q}_{\text {in }}$ are similar, except that the range of values of $Q_{0}$ (vertical position of the curves) depends solely on $\mathrm{Q}_{\text {in }}$. While increasing $\mathrm{Q}_{\text {in }}$ causes the curves to shift upwards, the latter widens in the $\mathrm{L} / \mathrm{G}$ range, and the troughs become wider as well.

\subsection{Effect of L/G Ratio on Liquid Accumulation Rate}

Figure 12 shows the variation of $\mathrm{Q}_{\mathrm{a}} / \mathrm{Q}_{\text {in }}$ with the liquidto-gas ratio, $\mathrm{L} / \mathrm{G}$. As $\mathrm{L} / \mathrm{G}$ is increased, the $\mathrm{Q}_{\mathrm{a}} / \mathrm{Q}_{\text {in }}$ values shows a peak, which migrates to the right as the inlet liquid flow rate is increased. Horizontally, $\mathrm{Q}_{\mathrm{a}}$ curves increases as $\mathrm{Q}_{\text {in }}$ increases. The turning point indicates that at higher $\mathrm{L} / \mathrm{G}$ ratio, that is higher liquid inlet flow rate at constant gas flow rate, the $\mathrm{Q}_{\mathrm{a}} / \mathrm{Q}_{\text {in }}$ decreases as a result of higher $\mathrm{Q}_{\text {in. }}$. Similarly, increasing $\mathrm{Q}_{\text {in }}$ raises the vertical position of the turning points. Moreover, higher $\mathrm{Q}_{\text {in }}$ leads to higher $\mathrm{Q}_{\mathrm{a}}$ as stated before.

\section{Conclusions}

It can be concluded from the above findings that:

1) The outlet liquid flow rate from the scrubber depends strongly on the inlet liquid flow rate. However, at a very high inlet liquid flow rate the outlet liquid flow rate do not increase further, indicating possibility of flooding.

2) Despite the fact that the rate of accumulation increases with $\mathrm{Q}_{\text {in }}$, the profiles of $\mathrm{Q}_{\mathrm{a}}$ versus $\mathrm{Q}_{\text {in }}$ are different from those of $\mathrm{Q}_{0}$.

3) The accumulation ate is always higher than the liquid outlet flow rate except for $\mathrm{Q}_{\text {in }}$ ranging between

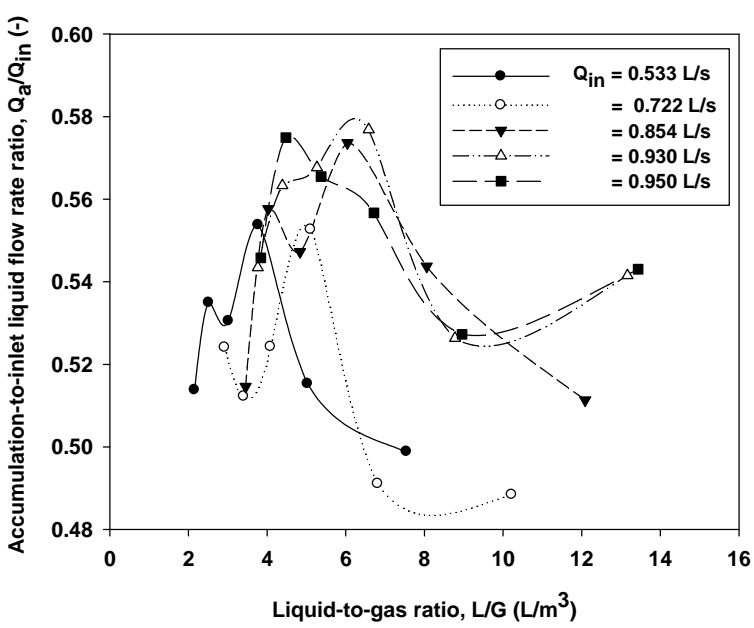

Figure 12. Values of $Q_{a}$ at different liquid-to-gas ratios and specific inlet liquid flow rates in the wet scrubber.

0.53 and $0.75 \mathrm{~L} / \mathrm{s}$, in which $\mathrm{Q}_{\mathrm{a}}=\mathrm{Q}_{\mathrm{o}}$, and $\mathrm{Q}_{\mathrm{a}}=\mathrm{Q}_{\text {in }} / 2$. This range defines the safe operating range without regime change towards flooding.

4) The slight decrease in the outlet-to inlet liquid flow rate ratio, $\mathrm{Q}_{\mathrm{o}} / \mathrm{Q}_{\text {in }}$ for $\mathrm{Q}_{\text {in }}>0.5 \mathrm{~L} / \mathrm{s}$ signifies that $\mathrm{Q}_{\mathrm{o}}$ remains constant even when $\mathrm{Q}_{\text {in }}$ is increased further. This observation is important to the operation of the wet scrubber as flowing can be avoided by limiting $Q_{\text {in }}$.

5) The initial decrease in $Q_{a} / Q_{\text {in }}$ indicates that $Q_{a}$ is always lower than $Q_{\text {in. }}$. However, the slight increase in $\mathrm{Q}_{\mathrm{a}} / \mathrm{Q}_{\text {in }}$ at higher inlet liquid flow rate is an indication of $\mathrm{a}$ change in flow regime towards flooding, which can be avoided by observing the liquid accumulation height, $\mathrm{H}_{\mathrm{a}}$.

6) When compared, the difference between $Q_{a} / Q_{\text {in }}$ and $\mathrm{Q}_{\mathrm{o}} / \mathrm{Q}_{\text {in }}$ decreases to zero as $\mathrm{Q}_{\text {in }}$ is increased between 0.53 and $0.72 \mathrm{~L} / \mathrm{s}$, beyond which the difference increases again.

7) The gas flow rate towards the wet scrubber has slight effect on $\mathrm{Q}_{\mathrm{o}}$ and $\mathrm{Q}_{\mathrm{a}}$ if the inlet liquid flow rate is maintained constant. This implies that since the incineration cycle is always carried out at constant liquid flow rate, below the flooding point, then the scrubber hydrodynamics is not affected even when the changes in flue gas flow rate due to combustion and blower action are extremely high.

8) The liquid-to-gas ratio, L/G, strongly affects both $\mathrm{Q}_{\mathrm{o}}$ and $\mathrm{Q}_{\mathrm{a}}$ and hence $\mathrm{Q}_{\mathrm{o}} / \mathrm{Q}_{\text {in }}$ and $\mathrm{Q}_{\mathrm{a}} / \mathrm{Q}_{\text {in }}$. The relationship between $\mathrm{L} / \mathrm{G}$ and the liquid flow rate ratios shows maximum turning points in different zones along the $\mathrm{L} / \mathrm{G}$ axis.

\section{Acknowledgements}

The author is grateful for the financial support from SIDA/Sarec core support through the University of Dar es Salaam. 


\section{REFERENCES}

[1] C. D. Cooper and F. C. Alley, "Air Pollution Control: A Design Approach," Prospect Heights, III, Wavelans Press, 1986.

[2] W. R. Carson, W. C. Nobles, M. H. Anderson and T. J. Boyd, "Electrostatic Precipitation Test Program at TVA's 20 MW FBC Pilot Plant," Proceedings of the 9th International Conference on CFB Combustion, 1987.

[3] E. P. Columbus, "Series Cyclone Arrangements to Reduce Gin Emissions," Transactions of ASAE, Vol. 36, No. 2, 1993, pp. 545-550.

[4] J. D. McKenna and J. H. Turner, "Fabric Filter-Baghouses I, Theory, Design, and Selection, Roanoke," ETS, VA, 1989.

[5] S. A. Fraser, S. Maartmann, E. Pollock and V. Razbin, "Evaluation of Electrostatic Precipitators versus Baghouses for a 150 MWe Utility CFB Boiler," Proceedings of the 10th International Conference on CFB Combustion, 1989.

[6] G. P. Greiner, "Fabric Filter-Baghouses II-Operation, Maintenance, and Trouble Shooting (A User's Manual)," Valley Printers, Salem, 1993.
[7] Y. Chang and M. Chen, "Industrial Waste to Energy by CFB Combustion," Resources, Conservation and Recycling, Vol. 9, 1993, pp. 281-294.

[8] S. Calvert, "Engineering Design of Fine Particle Scrubbers," Journal of the Air Pollution Control Association, Vol. 24, No. 10, 1974, pp. 929-934. doi:10.1080/00022470.1974.10469990

[9] S. Calvert, "Particle Control by Scrubbing," In: S. Calvert and H. M. Englund, Eds., Handbook of Air Pollution Technology, Willey, New York, 1984.

[10] S. Calvert, "Scrubbing," In: A. C. Stern, Ed., Air Pollution, Vol. IV, Academic Press, New York, 1977.

[11] S. Calvert, J. Goldschmid, D. Leith and D. Mehat, "Wet Scubber System Study," In: Scrubber Handbook, Vol. 1, US Department of Commerce, NTIS, PB-213016, 1972.

[12] M. M. Said and S. V. Manyele, "Hydrodynamics of the Multistage Wet Scrubber Coupled to a CFB Incinerator," African Journal of Environmental Science and Technology (AJEST), 2010.

[13] A. J. Bourncore and W. T. Davis, "Air Pollution Engineering Manual," Van Nostrand Reinhold, New York, 1992. 